\title{
RISK WORKSHOP IN HONOUR OF HANS BUEHLMANN FLORENCE 6-8 OCTOBER 2005
}

We renew the invitation to contribute with submission of papers to the Workshop "New Mathematical Methods in Risk Theory", which will take place in Florence on 6-8 October 2005, to celebrate Hans Bühlmann's 75th anniversary.

Titles and abstracts of contributed papers can be submitted by the on-line procedure activated in the Workshop web page, http://www.riskworkshop.it

Here is a list of useful information (for details, please see the above mentioned site).

1) Extended deadline for abstract submission: the new deadline is 30 June, 2005

2) Registration: you can register on-line at the Workshop web page. The registration fee (100 Euros if you register before 15 September 2005) covers: Workshop information/documentation (including the abstracts CD-ROM); Coffee breaks; Welcome reception (October 6); Workshop dinner (October 7).

3) Accommodation: on the workshop site you can find a list of suggested hotels, both in the City Center and in the Workshop Venue area, which are willing to offer discounts to the Workshop participants. Our strong recommendation is to book a hotel as soon as possible, since in Florence it is always highseason!

We look forward to meet you in Florence.

Marcello Galeotti, Cecilia Mancini

(for the Organizing Committee) 